\title{
OS MÉTODOS DAS CIÊNCIAS, O PARADIGMA INDICIÁRIO E AS PESQUISAS DOCUMENTAIS EM GEOGRAFIA: UMA PROPOSTA APLICADA
}

\author{
Bruno Falararo MELLO 1 \\ João Pedro PEZZATO 2
}

\begin{abstract}
Resumo
Este artigo é parte de pesquisa documental que relaciona o currículo de Geografia, em especial os conteúdos da climatologia escolar em livros didáticos do Ensino Médio, com sua respectiva ciência de referência. Na pesquisa em questão, foram selecionados autores de livros didáticos representativos da Geografia escolar brasileira entre os anos de 1967 e 2013, com o objetivo de proceder a uma leitura crítica acerca dos conteúdos de climatologia veiculados em suas obras didáticas, bem como a detalhes das narrativas que remetem às representações de seus autores. O escopo deste artigo, especificamente, é divulgar parte do que pesquisamos, a saber, o método norteador da pesquisa: o paradigma indiciário, apresentado pelo historiador italiano Carlo Ginzburg, que ainda é pouco conhecido na Geografia brasileira e que pode servir às pesquisas de fontes documentais, como a que realizamos. Apresentaremos algumas considerações sobre os métodos comumente empregados nas ciências e trataremos especificamente do paradigma indiciário, com exemplos de seu emprego extraídos da pesquisa.
\end{abstract}

Palavras-Chave: Ensino de Geografia. Geografia escolar. Livro didático. Método.

\section{SCIENCE METHODS, INDICIARY PARADIGM AND DOCUMENTAL RESEARCH IN GEOGRAPHY: AN APPLIED PROPOSAL}

\begin{abstract}
This paper is part of a documentary research that links the Geography curriculum, especially the contents of school climatology in high school textbooks, with their respective reference science. In the research in question, authors of didactic books representative of Brazilian school geography between the years of 1967 and 2013 were selected, with the objective of proceeding to a critical reading about the climatology contents conveyed in their didactic works, as well as details of the narratives that refer to the representations of their authors. The scope of this paper, specifically, is to disclose part of what we have researched, namely, the guiding method of the research: the indiciary paradigm, presented by the Italian historian Carlo Ginzburg, which is still little known in Brazilian

\footnotetext{
${ }^{1}$ Doutor pelo Programa de Pós-Graduação em Geografia da Universidade Estadual Paulista Júlio de Mesquita Filho (UNESP) - Rio Claro. E-mail: brunofmello@yahoo.com.br

${ }^{2}$ Professor Adjunto da Universidade Estadual Paulista Júlio de Mesquita Filho (UNESP) - Rio Claro. E-mail: joaopezzato@hotmail.com
} 
Geography and which can serve searches of documentary sources, such as the one we carry out. We will present some considerations about the methods commonly used in the sciences and we will deal specifically with the indiciary paradigm, with examples of their employment from research.

Keywords: Geography teaching. School geography. Textbook. Method.

\section{LES MÉTHODES DES SCIENCES, LE PARADIGME INDICIAIRE ET LA RECHERCHE DOCUMENTAIRE EN GÉOGRAPHIE: UNE PROPOSITION APPLIQUÉE}

\section{Résumé}

Cet article fait partie d'une recherche documentaire qui relie des programmes de géographie, en particulier le contenu de la climatologie scolaire dans les manuels du secondaire, avec leur science de référence respective. Dans la recherche en question, des auteurs de livres didactiques représentatifs de la géographie scolaire brésilienne au cours des années 1967-2013 ont été sélectionnés, dans le but de procéder à une lecture critique des contenus climatologiques véhiculés dans leurs travaux didactiques, ainsi que détails des récits qui renvoient aux représentations de leurs auteurs. Le but de cet article, en particulier, est de divulguer une partie de ce qu'on a recherché, c'est-à-dire, la méthode directrice de la recherche: le paradigme indiciaire, présenté par l'historien italien Carlo Ginzburg, qui est encore peu connu en géographie brésilienne et qui peut servir à la recherche à partir de sources documentaires, comme celle qu'on a réalisée. On présentera quelques réflexions sur les méthodes couramment utilisées dans les sciences et on traitera spécifiquement du paradigme indiciaire, avec des exemples de leur utilisation extraits de la recherche.

Mots-Clés: Enseignement de la géographie. Géographie scolaire. Manuel scolaire. Méthode.

\section{INTRODUÇÃO}

A palavra método é de origem grega e significa, literalmente, "caminho para” - junção dos termos gregos metá [ $\mu \varepsilon \tau a \dot{~-~ p o r ~ m e i o ~ d e, ~ p a r a] ~ e ~ h o d o ́ s ~[o ́ \delta o ̀ s ~}$ - caminho]. Quando falamos em método, é comum se pensar em uma série de procedimentos que devemos realizar para alcançar algum resultado que se espera, em qualquer campo de atuação, quais sejam, pesquisas científicas, investigações filosóficas, produção industrial etc.

Argumenta Ruiz (1996, p. 137) que “o método constitui característica tão importante da ciência que, não raro, identificamos ciência com método”. De fato, quando analisamos mais atentamente as questões de método, descobrimos que os homens procuraram, a priori, agir cientificamente, e somente a posteriori é que pararam para examinar os caminhos tomados durante suas investigações. 
Os métodos das ciências, o paradigma indiciário e as pesquisas documentais em Geografia: Uma proposta aplicada

O método é fruto de uma reflexão sobre a forma de conduzir as ciências para os fins desejados. Para Alves-Mazzoti e Gewandsznajder, "um método pode ser definido como uma série de regras para tentar resolver problemas” (2001, p. 3). Nesse sentido, o termo "regra" está vinculado à "fórmula que indica ou prescreve o que deve ser feito num caso determinado: preceito moral, ou lógico" (LALANDE, sd., vol. 2, p. 402).

Desde os primeiros anos da vida escolar, quando nos são apresentadas as disciplinas do currículo e tomamos o primeiro contato com os saberes científicos, somos inclinados a pensar que o método está intimamente vinculado às ciências naturais. São elas as que revelam a natureza do mundo e das coisas de maneira mais evidente: aprendemos na prática de um experimento, na manipulação de um objeto ou de reagente em um laboratório, na observação de algum pequeno animal.

As ciências naturais gozam de alto prestígio na sociedade contemporânea. Como seus objetos de investigação e suas variáveis relacionadas podem ser controlados sob determinadas condições, testados e depois reproduzidos, elas produzem resultados concretos e pontuais, passando a impressão de serem a forma mais superior de ciência (RAMPAZZO, 2013, p. 55). A isso soma-se o aporte da quantificação, um dos apanágios da ciência moderna e sem a qual qualquer pesquisa careceria - em tese, frisemos - de substancialidade.

\section{OS MÉTODOS DAS CIÊNCIAS NATURAIS, DAS CIÊNCIAS HUMA- NAS E O APORTE MATEMÁTICO}

Os métodos tradicionalmente atribuídos às ciências naturais, sem prejuízo de eventuais subclassificações que se possam fazer, são a experimentação, a indução e a dedução. Por experimentação entende-se pôr a teste o objeto de estudo. Após o teste, se satisfeitas as prévias especulações (ou hipóteses) do observador, os resultados poderão ser reduzidos a uma linguagem matemática. Rampazzo (2013, p. 31) cita o exemplo de Galileu Galilei, para quem a meta de qualquer pesquisa científica seria a descoberta das quantidades que se encontram no fenômeno observado. 
A indução3 é correntemente aceita como o processo de raciocínio que parte de uma proposição particular para uma conclusão ampliada em lei ou regra mais geral. O exemplo clássico que podemos fornecer é aquele do cisne: observa-se um que é branco; depois outro, também, branco; ainda um terceiro, da mesma cor, e assim por diante, até que todos os cisnes vistos sejam brancos.

O observador concluirá, facilmente, que todos os cisnes do mundo são brancos. Ao partir de uma proposição particular (um grupo de cisnes brancos), a premissa é alargada até abarcar toda a totalidade daquele universo. É evidente que esse método tem grande tendência ao erro. Bastaria um único cisne não branco - um negro, por exemplo - para invalidar o raciocínio. Desde o filósofo David Hume, no século XVIII, o problema da indução vem sendo debatido. Uma possível solução foi apresentada pelo filósofo Karl Popper, no século XX, em sua obra A lógica da pesquisa científica: a afirmação baseada em método indutivo seria válida até que alguma nova evidência demonstrasse o contrário do que fora proposto (como no caso do cisne negro). A isso deu o nome de falseabilidade, cuja intenção é demarcar o que é ou não é ciência (ciência, aqui, entendida como investigação da natureza). Karl Raimund Popper (1902-1994) é considerado um dos filósofos mais influentes do século XX e destacou-se pela sua ideia de falseabilidade (ou refutabilidade) como um critério da demarcação do conhecimento científico e pela sua defesa da sociedade aberta. A falseabilidade proposta por Popper, embora tenha sido alvo de críticas dos cientistas Thomas Kuhn, Paul Feyerabend e Imre Lakatos, permanece como uma das formas mais eficazes de garantir a uma proposição baseada no método da indução sua legitimidade no campo das ciências naturais, porque a capacidade de submeterse à prova mediante novas evidências é que dá ao conhecimento a oportunidade de consolidar-se. 4

Santos (1988, p. 49) nos alerta que a ciência moderna desconfia das evidências da experiência imediata. Ao contrário da ciência aristotélica, em que

\footnotetext{
${ }^{3}$ Rampazzo (2013, p. 38) afirma que a "indução é a alma das ciências experimentais", o que não quer dizer que não possa ser usada pelas ciências humanas IN: RAMPAZZO, Lino. Metodologia científica: para alunos dos cursos de graduação e de pós-graduação. $7^{\mathrm{a}}$ ed. São Paulo: Loyola, 2013.

${ }^{4}$ ALVES-MAZZOTI, Alda Judite e GEWANDSZNAJDER, Fernando. O método das ciências naturais e sociais: pesquisa quantitativa e qualitativa. 2. ${ }^{a}$ ed. São Paulo: Pioneira Thompson Learning, 2001, passim.
} 
a evidência por si só bastava, sendo reveladora da verdade5 sobre o objeto observado, na ciência moderna a simples evidência não basta, porquanto ela está na base do conhecimento vulgar e, por extensão, ilusório. O exemplo trazido pelo autor diz respeito ao mesmo Galileu, ora citado. Galileu empreendeu largos esforços no sentido de demonstrar que a hipótese dos movimentos de rotação e de translação da Terra não é refutada somente pelo fato de que não observamos os efeitos mecânicos desses movimentos, ou seja, por a Terra nos parecer parada. Outro fato destacado pelo autor é que a separação entre natureza e pessoa humana é um marco da ciência moderna.

A experiência, por si só, diferentemente do que se pode pensar, não dispensa a teoria prévia, o pensamento dedutivo ${ }^{6}$ ou a especulação. De acordo com Santos (1988, p. 50), Einstein chamou a atenção para o fato de os métodos experimentais empregados por Galileu serem imperfeitos a ponto de só por via especulativa poderem ser preenchidas as lacunas entre os dados empíricos. Esse dado é revelador por nos mostrar que não basta à ciência apenas experiência e indução. É preciso algo mais que lhe dê suporte para fazer-se conhecimento válido e diferente de outras formas de conhecimento.

Desse modo, conforme pontua brilhantemente Santos,

As ideias que presidem à observação e à experimentação são as ideias claras e simples a partir das quais se pode ascender a um conhecimento mais profundo e rigoroso da natureza. Essas ideias são as ideias matemáticas. A matemática fornece à ciência moderna não só o instrumento privilegiado de análise, como também a lógica da investigação, como ainda o modelo de re-presentação da própria estrutura da matéria. Para Galileu, o livro da natureza está inscrito em caracteres geométricos e Einstein não pensa de modo diferente. Deste lugar central da matemática na ciência moderna derivam duas consequências principais. Em primeiro lugar, conhecer significa quantificar. $\mathrm{O}$ rigor científico afere-se pelo rigor das medições. [...] O que não é quantificável é cientificamente irrelevante. Em segundo lugar, o método científico assenta na redução da complexidade. $\mathrm{O}$

\footnotetext{
${ }^{5}$ Sobre a definição de verdade, diz Aristóteles: "O conhecimento se diz verdadeiro enquanto exprime conformidade com a realidade; falso, porém, enquanto apresenta discordância com a realidade (ARISTÓTELES apud RUIZ, 1996, p. 116). Em outras palavras, a verdade, para Aristóteles, é a adequação do intelecto à realidade que se nos apresenta. Ainda Ruiz (1996, p. 116): "A verdade nasce, pois, do julgamento da mente a respeito das realidades e não existe sem ele".

${ }^{6}$ Que parte de uma proposição geral para uma proposição particular. O pesquisador parte de princípios reconhecidos como verdadeiros, chamados de premissa maior, e estabelece relações com uma segunda proposição, chamada de premissa menor. Desta forma, a partir do raciocínio lógico, chega-se à verdade daquilo que se é proposto, a conclusão. A conclusão nunca pode ser maior do que suas premissas.
} 
mundo é complicado e a mente humana não o pode compreender completamente. Conhecer significa dividir e classificar para de-pois poder determinar relações sistemáticas entre o que se sepa-rou. [...] A divisão principal é a que distingue entre "condições iniciais" e "leis da natureza". [..] Essa distinção entre condições iniciais e leis da natureza nada tem de "natural". Como bem ob-serva Eugene Wigner, é completamente arbitrária. No entanto, é nela que assenta toda a ciência moderna (SANTOS, 1988, p. 50).

Parece-nos claro, então, que a matemática7 exerce um papel fundamental nas ciências naturais. Devemos refletir, entretanto, se isso valeria também para outros campos do saber. No entender de Alves-Mazzoti e Gewandsznajder (2001, p. 121), a linguagem matemática não é necessariamente essencial a outros ramos da ciência. Apoiando-se na proposição de Ziman (1996), os autores sustentam que a exigência fundamental à construção da ciência é de que a mensagem seja expressa de forma clara e significativa, permitindo que outros pesquisadores da área participem do diálogo e o ampliem.

As ciências humanas investigam o homem. Em tese, diferem das ciências naturais por não demarcarem tão claramente os limites entre o sujeito e o objeto, ou seja, porque investigador (sujeito) e investigado (objeto) situam-se no mesmo plano. O sujeito cognoscente, nesse caso, encontra-se naturalmente vinculado a seu objeto, sem que isso traga prejuízo aos resultados da sua pesquisa. As ciências naturais não os admitem no mesmo plano, obviamente, porque seu objeto de estudo não é o homem.

Considerando a subjetividade como elemento integrante da produção de conhecimento, a não separação do sujeito que conhece seu objeto de conhecimento e, no contexto do debate entre ciências humanas e naturais, a defesa de que os resultados das pesquisas são mais uma "construção social” que uma descrição da natureza, Demo coloca:

O conhecimento metodológico sugere uma postura frente à realidade e à prática social. Assim, é importante distinguir métodos e técnicas, apesar de existir uma relação indissociável entre ambos. $\mathrm{O}$ método exige técnicas condizentes à postura adotada pelo sujeito. (...) Enquanto o método decorre da concepção de mundo, a técnica constitui um conjunto de

\footnotetext{
${ }^{7}$ A matemática ocupa um lugar à parte nas ciências, sendo denominada de ciência formal. Não é uma ciência natural, obviamente, porque não lida com experimentação nem com indução, sendo que seu método é unicamente a dedução lógico-formal. Inobstante, ela é o substrato em que se apoiam as ciências naturais.
} 
processos destinados a produzir os instrumentos necessários para o conhecimento dessas relações. Em síntese, a metodologia é o conjunto de decisões a serem tomadas a partir de uma visão de mundo do sujeito que conhece (DEMO, 1997, p. 27-45).

Não entraremos no mérito das diferenças entre ciências humanas (ou humanidades) e ciências sociais, cujo debate é longo e controverso. Basta-nos, para o que intentamos, a compreensão de que tanto uma quanto a outra partem do mesmo objeto - o homem -, analisando suas múltiplas dimensões. Corrêa (2000, p. 28), por seu turno, afirma que "a história, a antropologia, a economia, a geografia e a sociologia, entre outras ciências sociais, estudam a sociedade”, sendo, por isso, ciências sociais. Partimos, aqui, do pressuposto que as humanidades são uma categoria que abriga as ciências sociais.

A questão do método parece ser o calcanhar de Aquiles das ciências humanas. Por ter um objeto que pensa, age e se encontra no mesmo plano do sujeito, torna-se mais delicada a aplicação direta dos métodos costumeiramente empregados pelas ditas ciências naturais. Se, conforme afirma Rampazzo (2013, p. 33), “a ciência moderna foi se afirmando, integrando a observação (Bacon), a experimentação (Galileu) e a dedução matemática (Descartes)”, devemos nos questionar até que ponto esses métodos satisfazem as condições das próprias ciências naturais e se atendem também às humanidades. Cabem-nos algumas reflexões a esse propósito.

Alves-Mazzoti e Gewandsznajder (2001) destacam dois tipos de pesquisa: a pesquisa quantitativa para as ciências naturais e a pesquisa qualitativa para as ciências sociais ${ }^{8}$. A pesquisa quantitativa tem sua raiz no positivismo lógico. $\mathrm{O}$ termo positivismo origina-se do filósofo francês Saint Simon9, de quem Auguste Comte foi secretário. Todavia, coube a Comte a divulgação e popularização do termo. Para ele, a ciência, baseada na observação e na indução, seria o modelo de todo o conhecimento. A lógica e a matemática, por se constituírem em conhecimentos a priori, ou seja, independentes de experiência e dedutivos, serviriam de aporte à construção de leis sobre o funcionamento da natureza e dos seres.

No caso da tradicional grande divisão das ciências, esclarece Santos que

\footnotetext{
${ }^{8}$ Os autores empregam a nomenclatura "ciências sociais".

${ }^{9}$ Cf. ABBAGNANO, Nicola. Dicionário de filosofia. $2^{\text {a }}$ ed. São Paulo: Mestre Jou, 1982, p. 746.
} 
A ciência social será sempre uma ciência subjetiva e não objetiva como as ciências naturais [...] para o que é necessário utilizar métodos de investigação e mesmo critérios epistemológicos diferentes dos correntes nas ciências naturais, métodos qualitativos em vez de quantitativos, com vista à obtenção de um conhecimento intersubjetivo, descritivo e compreensivo, em vez de um conhecimento objetivo, explicativo e nomotético (SANTOS, 1988, p. 53).

De fato, a tentativa de enquadramento das ciências humanas nos métodos tradicionalmente usados pelas ciências naturais evidencia uma atitude, o mais das vezes, improducente. Se investigamos o homem, suas ações e suas produções, conduzir uma pesquisa de humanidades nos moldes do positivismo lógico - usando a experimentação, a reprodução sob condições de controle de variáveis, a descrição e a tentativa de estabelecimento de normais gerais com aporte matemático - não pode ser exitoso. O problema, então, é de ordem metodológica.

Ainda sobre o imputado rigor e infalibilidade da matemática, é Santos (1988, p. 56) quem, mais uma vez, nos adverte: “[...] as investigações de Gödel ${ }^{10}$ vêm demonstrar que o rigor da matemática carece ele próprio de fundamento. A partir daqui é possível não só questionar o rigor da matemática como também redefini-lo enquanto forma de rigor que se opõe a outras formas de rigor alternativo [...]”. O autor quer dizer que a matemática, veículo formal alçado à condição de baluarte da ciência positivista, não é tão rigorosa como se quer fazer crer; ela própria não passa, também, de uma convenção humana e não é, ao contrário do que possa parecer, naturalmente dada ou evidente, nem neutra. Esse argumento é baseado principalmente no teorema da incompletude (ou do não-complementamento) desenvolvido por Gödel, segundo o qual é possível formular proposições indecidíveis, que não podem ser refutadas nem demonstradas, mesmo seguindo à risca as regras da lógica matemática dentro de um dado sistema formal. Em suma, o teorema da incompletude de Gödel foi um duro golpe ao positivismo lógico, pois a matemática está, também, sujeita ao

${ }^{10}$ Kurt Friedrich Gödel (Brünn, Áustria-Hungria, 28 de abril de 1906 - Princeton, Estados Unidos, 14 de janeiro de 1978) foi um filósofo, matemático e lógico austríaco, naturalizado norte-americano. Considerado, ao lado de Aristóteles, Alfred Tarski e Gottlob Frege, um dos mais importantes lógicos da história, Gödel causou um imenso impacto no pensamento científico e filosófico no século 20, época em que nomes como Bertrand Russell, Alfred North Whitehead e David Hilbert analisavam o uso da lógica e da teoria dos conjuntos como instrumento para compreender os fundamentos da matemática de Georg Cantor. 
Os métodos das ciências, o paradigma indiciário e as pesquisas documentais em Geografia: Uma proposta aplicada

ponto de vista assumido pelo pesquisador, que é capaz de fazer dela o uso que melhor lhe convier.

Comentamos acerca dos métodos mais comuns das ciências naturais. Mas mesmo algumas das ciências tradicionalmente inseridas nesse campo do saber têm dificuldade de se enquadrar no tripé empirismo-induçãoquantificação. Um exemplo que pode ser dado é a climatologia. Embora delimitada como uma ciência natural, por estudar a atmosfera terrestre, o clima, o tempo e todas as interações dos elementos e dos fatores climáticos, como poderíamos tentar reproduzir em laboratório, independentemente de tempo e espaço, um evento que ocorre espontaneamente na natureza, como uma frente fria ou uma chuva?

Potapova (2008, p. 87) diverge quanto à rígida divisão entre as ciências naturais e humanas, que remonta ao século XIX, quando do nascimento da sociologia e áreas afins. Para ela, a Geologia (e, por extensão, as Geociências), antes de serem ciências naturais, são ciências históricas da natureza.

Pode ser surpreendente o fato de alguém conseguir enxergar uma categoria cara às ciências humanas - o tempo - em uma ciência tradicionalmente classificada como natural e exata, que justamente deveria prescindir dele. Quando nos referimos a prescindir, invocamos o princípio das ciências naturais de que os experimentos podem ser reproduzidos em qualquer lugar, a qualquer tempo.

Todavia, a Geologia é uma ciência que tem por finalidade a investigação das rochas, minerais e eventos a eles relacionados em uma escala temporal. Quando falamos em escala temporal em Geologia, é inevitável pensar em interpretação dos fenômenos observados em campo. A interpretação de um fenômeno requer um esforço heurístico que está além de uma simples descrição. Como bem salientam Alves-Mazzoti e Gewandsznajder (2001, p. 125), "outra razão apontada por Boudon (1991) para a recusa do status de ciência às ciências humanas se refere ao fato de que seu objetivo nem sempre é explicativo, podendo ser interpretativo" (grifos nossos).

Frodeman (2001, p. 55) concorda com Potapova quanto ao caráter de ciência histórica da Geologia, argumentando que também a Cosmologia, a Paleontologia, a Antropologia e a História do Homem são ciências históricas. A razão para assim as denominar é que tais ramos do conhecimento têm 
necessidade de lidar com eventos ocorridos em um dado tempo. Para tanto, é fundamental que haja consistentes interpretações dos eventos investigados por essas ciências, o que se faz valendo-se de um método próprio das ciências humanas: a hermenêutica.

Diferentemente das ciências experimentais (de que os melhores exemplos, para o autor, são a física e química), cujo escopo são previsões pela combinação de leis universais com a descrição de condições iniciais - o que se intitula método dedutivo-nomológico ${ }^{11}$, as ciências históricas não se empenham em fazer previsões, mas, antes, interpretações da realidade (FRODEMAN, 2001, p. 55). Para o autor, enquanto espaço e tempo não têm lugar nas ciências experimentais, eles são fundamentais para as ciências históricas da natureza. Por essa razão é que os experimentos em Geologia, em Climatologia ou em quaisquer das geociências só podem ser reproduzidos em laboratório com muitas ressalvas. Portanto, faz-se crucial nas geociências a compreensão de que os fenômenos analisados dependem do conhecimento prévio do cientista e de interpretação e contextualização.

\section{O PARADIGMA INDICIÁRIO}

Há ramos do conhecimento que, embora tradicionalmente se valham de métodos das ciências naturais, não se encaixam muito bem nas balizas do positivismo lógico. Um exemplo típico é a medicina. Um médico inicia sua investigação com base nas descrições do seu paciente. Com base no que lhe é relatado pelo paciente e no que nele vê, esse médico procura nos indícios e nos sinais as possíveis causas da enfermidade que o acomete. De outra maneira dito, é com base nos indícios e nos sinais que o profissional principia seu diagnóstico.

Indícios e sinais são parte de uma proposta de método que prima pela interpretação dos fenômenos observados. Por interpretação, conforme pontuamos, entendemos um esforço que vai além da descrição de um evento ocorrido, por exemplo, em laboratório, sob condições de controle de variáveis, cujo tempo e espaço não são preponderantes aos resultados finais - para isso, os métodos experimentais, indutivos e nomotético-dedutivos são suficientes. Porém, em se

\footnotetext{
${ }^{11}$ As ciências naturais valem-se tanto da indução, que parte da experiência sensível para procurar compreender os fenômenos, quanto da dedução, que visa à explicação do fenômeno, validação de hipóteses e formulação de teorias ou leis gerais.
} 
tratando de ciências humanas, cujo objeto é o homem (e, por extensão, sua produção), o ato de interpretar o que se estuda, em que pese apenas a descrição, assume posição de alta relevância.

O que é interpretar? Segundo definição do minidicionário Aurélio (2004, p. 486), entre outras acepções, é “1. Ajuizar a intenção, o sentido de. 2. Explicar ou declarar o sentido de (texto, lei etc.)”. Ao partir dessa definição, o pesquisador renuncia, em primeiro plano, ao pressuposto da neutralidade, já que, ao interpretar seu objeto, assume uma intenção e pode se colocar no lugar dele. Não existe interpretação sem posição. As ciências humanas, tendo preferido a compreensão do mundo à manipulação do mundo, resistiram à separação sujeito-objeto (SANTOS, 1988, p. 63).

A interpretação dos fenômenos ${ }^{12}$ está vinculada a dois métodos largamente utilizados nas ciências humanas: a fenomenologia e a hermenêutica. Cada uma, a seu modo, os interpreta de modo particular. No tocante à hermenêutica, Chinazzo traz a seguinte definição:

[...] A hermenêutica é a ciência que estabelece os princípios, as leis e os métodos de interpretação. É a teoria que interpreta os

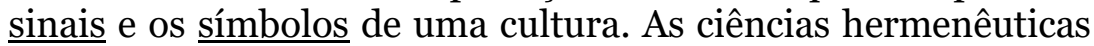
são consideradas as ciências humanas ou as ciências do espírito [...]. As ciências hermenêuticas estudam o universo da cultura. Os fenômenos humanos estariam associados a significados, tanto para os agentes como para os espectadores. Essas ciências trabalham essencialmente com a categoria do sentido. A metodologia de decifrar ou interpretar um texto proporcionalhes seu modelo. Em outras palavras, a hermenêutica busca atingir a palavra ou o sentido do que acontece na cultura, analisando o modo de ser dos homens, pois a ação humana se revela sempre cheia de sentido (Sinnhaft) e carregada de valor (Wertbezogen) (CHINAZZO, 2013, p. 141-142, grifos nossos).

12 Para Rampazzo (2013, p. 53), haveria uma distinção entre fato e fenômeno. O fato é a realidade em si mesma, pronta e independente dos sujeitos. $\mathrm{O}$ fenômeno é a forma como o sujeito cognoscente percebe o fato com o uso da faculdade da razão e da sensibilidade; é, portanto, algo particular. Trata-se de uma linha de pensamento kantiana, pois, de acordo com Kant, a realidade ou essência dos seres - a coisa em si - não pode ser conhecida, mas tão somente conhecemos o que está acessível aos nossos sentidos - a realidade - por meio das categorias do nosso entendimento (a saber, realidade, negação e limitação = categorias de qualidade; unidade, pluralidade e totalidade = categorias de quantidade; substância, causalidade e comunidade $=$ categorias de relação; possibilidade, existência e necessidade $=$ categorias de modalidade). Com relação à nossa razão, podemos conhecer o que nos permitem as duas formas de intuição pura dadas a priori: o tempo e o espaço. A tentativa humana de conhecer a coisa em si, inalcançável pelos sentidos, intitula-se metafísica (ou filosofia primeira), que se vale da racionalidade para tentar responder a questões que fogem à sensibilidade direta. Porém, o conhecimento da realidade, para Kant, depende da junção da sensibilidade e da razão. 
A hermenêutica se traduz em um método eficaz para análise de obras escritas, quer literárias, históricas, documentais, jurídicas ou didáticas. No nosso caso, em se tratando de pesquisa de obras didáticas de Geografia, a análise e a interpretação dos conteúdos veiculados, em consonância com saberes acumulados pelos pesquisadores, traz à tona elementos, intencionais ou não, que podem passar despercebidos a um público-alvo ainda em formação intelectual (a saber, os alunos da educação básica). Após a análise, os elementos discursivos e eventuais intencionalidades dos autores das obras podem ser apontadas.

Ricœur (1990, p. 17) adota uma definição que consideramos enxuta e, ao mesmo tempo, carregada de significação: "[...] a hermenêutica é a teoria das operações da compreensão ${ }^{13}$ em sua relação com a interpretação dos textos”. Do mesmo modo, assim qualifica a interpretação:

Esta atividade de discernimento é, propriamente, a interpretação: consiste em reconhecer qual a mensagem relativamente unívoca que o locutor construiu apoiado na base polissêmica do léxico comum. Produzir um discurso relativamente unívoco na recepção das mensagens, eis o primeiro e o mais elementar trabalho de interpretação (RICEUR, 1990, p. 19).

O mesmo autor traz importantes considerações acerca da forma pela qual o método hermenêutico se firmou nas humanidades, ou ciências do espírito, como foram chamadas por Wilhelm Dilthey. A hermenêutica foi necessária para oferecer a essas ciências um estatuto de cientificidade no século XIX, em um momento em que elas surgiam e buscavam legitimar suas bases epistêmicas. Ela constituiria, em todo caso, "a camada objetivada da compreensão, graças às estruturas essenciais do texto" (RICEUR, 1990, p. 27). Uma compreensão que deveria conduzir à intepretação dos objetos analisados.

${ }^{13}$ É importante frisar que para Ricœur (1977, p. 126, 127, 145; 1990, p. 17, 18, 25 e 35), a quem tomamos por base, explicar e compreender são momentos relativos a um único e mesmo processo, a interpretação. Contrapondo-se a Wilhelm Dilthey, para quem a diferença do estatuto entre coisa natural e espírito comandaria a diferença entre o estatuto de explicar e compreender (ou seja, explicar seria a função das ciências naturais e compreender, a das ciências humanas), Ricœur assume a posição de Heidegger de que compreender é entender e que a explicação desenvolve analiticamente a compreensão. Desse modo, o autor esclarece que a interpretação é a relação dialética e indissociável entre explicar e compreender - a explicação é metódica, enquanto a compreensão é o momento não metódico que, nas ciências da interpretação, se compõe com o momento metódico da explicação. Não há, segundo sua visão, nem dualismo nem monismo entre os dois termos. 
Conforme expusemos, indícios e sinais compõem as peças-chaves para a interpretação, que pode ser de textos, de fenômenos sociais ou mesmo naturais (no caso das ciências históricas da natureza). Em se tratando de textos, esses indícios e sinais nos levariam a uma compreensão da intenção, quer revelada, quer oculta, do autor, e assim assumiríamos uma postura interpretativa.

Em seu ensaio seminal intitulado Sinais: raízes de um paradigma indiciário, Carlo Ginzburg (2016) apresenta o paradigma indiciário, modelo epistemológico interpretativo que, sustentamos, é uma vertente da hermenêutica ${ }^{14}$. Esse método está presente nas ciências humanas desde o final do século XIX, embora poucos tenham lhe dado a devida atenção. Segundo Ginzburg, os sinais e indícios sempre estiveram presentes na história da humanidade, a começar de seus primórdios, quando o homem era caçador. Desdobraremos melhor o método indiciário a partir de três exemplos.

$\mathrm{O}$ autor, em quem nos baseamos doravante, traça um paralelo interessante entre três figuras pertencentes a ramos muito distintos do saber, mas intimamente ligadas pelo mesmo método: o italiano Giovanni Morelli, o inglês Arthur Conan Doyle e o austríaco Sigmund Freud, respectivamente vinculados à pintura, à literatura e à medicina, e todos praticamente contemporâneos, havendo vivido de meados do século XIX ao início do século $\mathrm{XX}$.

Morelli foi o pioneiro na atribuição de autenticidade de quadros antigos. Entre 1874 e 1876, surgiu uma série de artigos de sua autoria (sob pseudônimo, inicialmente) em uma revista de arte alemã sobre um método bastante peculiar - e incomum - por ele desenvolvido para atribuir autenticidade a pinturas italianas que ele havia analisado.

Dizia Morelli que os museus estão cheios de quadros cuja atribuição de autoria era incorreta. Porém, era difícil encontrar o verdadeiro autor, porque os métodos tradicionais de cotejamento, a saber, as características mais vistosas dos mestres italianos nas obras, eram facilmente imitáveis. Desse modo, propôs uma maneira mais sutil de analisar as obras: examinar os pormenores mais negligenciáveis e menos influenciados pelas características da escola a que o

\footnotetext{
${ }^{14}$ Embora Ginzburg não ligue diretamente o paradigma indiciário à hermenêutica, parece-nos claro que ambos os métodos estão intimamente vinculados, pois partem do mesmo princípio: a interpretação.
} 
autor pertencia: os lóbulos das orelhas, as formas dos dedos das mãos e dos pés, as unhas etc.

Partindo do pressuposto de que os falsários prestavam muita atenção a características mais chamativas de obras consagradas (como olhares, sorrisos ou paisagens) e não davam a mesma atenção a detalhes que poucos observariam, Morelli compreendeu que a chave para a descoberta da autenticidade estava nos detalhes ignorados, nos pormenores, ou seja, nos signos pictóricos que estão visíveis, mas que só os mais atentos observam.

O método indiciário de Morelli foi aproximado por Castelnuovo (apud GINZBURG, 2016, p. 145) aos métodos investigativos empregados pelo detetive da ficção Sherlock Holmes (criado pelo escritor Conan Doyle). Holmes, tal qual Morelli, também se baseava em pistas, sinais e indícios nos casos que investigava. Como é amplamente sabido, sua especialidade consistia em desvendar casos complexos e aparentemente insolúveis por meio da observação sistemática das características do objeto investigado. Nada lhe escapava à vista. A solução sempre estava ligada a rastros deixados pelo criminoso que haviam passado despercebidos aos demais.

Freud, no início de sua carreira na medicina, tomou conhecimento dos ensaios de Morelli sobre as pinturas italianas. Anos depois, quando já era bastante conhecido no meio científico por suas pesquisas, ele reconheceu que o método de Morelli estava estreitamente ligado ao método da psicanálise. Mas o que a leitura dos textos de Morelli representaram realmente para Freud? Ginzburg nos explica:

É o próprio Freud a indicá-lo: a proposta de um método interpretativo centrado nos resíduos, sobre os dados marginais, considerados reveladores. Desse modo, pormenores normalmente considerados sem importância, ou até mesmo triviais, "baixos", forneciam a chave para aceder aos produtos mais elevados do espírito humano [...] (GINZBURG, 2016, p. 149-150).

Ou seja, um método que permitiu a Freud desvendar as mais profundas camadas do inconsciente humano baseando-se em pistas fornecidas pelos próprios pacientes, as quais nem eles próprios atribuíam grande importância.

Nos três casos citados, pequenas pistas permitiram capturar uma realidade mais profunda e, até então, desconhecida ou inatingível. Pistas, ou, mais 
precisamente, sintomas (no caso de Freud), indícios (no caso de Sherlock Holmes) e signos (no caso de Morelli). A singular convergência de método entre os três pode-se explicar pelo fato de que Freud, Morelli e Conan Doyle eram médicos (Morelli formou-se em medicina e Conan Doyle havia sido médico antes de se dedicar à literatura). Nos três casos, nota-se o modelo de semiótica médica, isto é, a disciplina que permite diagnosticar doenças inacessíveis à observação direta com base em sintomas superficiais, sinais e indícios que passam despercebidos aos olhos leigos. Novamente, é Ginzburg a nos esclarecer:

Mas não se trata simplesmente de coincidências bibliográficas. No final do século XIX - mais precisamente, na década de 1870-80 -, começou a se afirmar nas ciências humanas um paradigma indiciário baseado justamente na semiótica. Mas as suas raízes eram bem antigas (GINZBURG, 2016, p. 151).

Por raízes antigas o autor se refere à maneira como os homens usam os sinais para interpretar a realidade que os cerca, desde tempos imemoriais: basta trazermos à tona a atividade venatória ${ }^{15}$ dos homens das cavernas, que demandava todo um esforço interpretativo das marcas deixadas pelos animais em sua passagem.

Estamos assumindo o termo semiótica em sua acepção mais ampla, a saber, estudo dos signos, quer verbais, quer não-verbais. No caso da pesquisa documental que realizamos, trata-se da análise dos textos e imagens contidas em livros didáticos da disciplina de Geografia para o ensino escolar.

O método do paradigma indiciário, também chamado de indiciarismo, foi bem definido por Paziani e Perinelli Neto:

O indiciarismo de Ginzburg pode ser visto como um método de análise discursiva na qual o historiador, por exemplo, deve dedicar-se a tarefa de ler e interpretar intensivamente as fontes coletadas, vendo estas enquanto "discursos" que o auxiliem na compreensão das intenções subjetivas e dos expedientes narrativos presentes em um determinado "texto" (ou conjunto de "textos"), tanto em sua dimensão discursiva propriamente dita, quanto na dimensão extradiscursiva (a não-transparência da linguagem) (PAZIANI e PERINELLI NETO, 2018, p. 325).

${ }^{15}$ Relativa à caça. 
Segundo Paziani e Perinelli Neto (2018, p. 327), Carlo Ginzburg, em sua obra Relações de força (2002), coloca no centro do debate a questão da busca e dos sentidos da verdade por meio das relações entre retórica e prova. Para Ginzburg, a perspectiva de que os historiadores - e aqui podemos ampliar o leque e incluir também os geógrafos - possam provar algo parece ser antiquado e ridículo. Sobre a concepção de prova retórica de Ginzburg, os autores argumentam que

Sua concepção de "prova retórica" consiste num pressuposto de entendimento das narrativas históricas enquanto possibilidades de construção de conhecimentos situados, mas cujo sentido aponta para a busca da verdade (e da "objetividade") - mesmo que tal sentido de busca seja "intrinsecamente seletivo e parcial”. (GINZBURG, 2002, p. 43, apud PAZIANI e PERINELLI NETO, 2018, p. 329).

Apesar de considerar que uma narrativa histórica é sempre constituída por subjetividade, criatividade e imaginação do investigador, Ginzburg (2002, p. 43, apud PAZIANI e PERINELLI NETO, 2018, p. 329) advoga que o conhecimento é possível, em um diálogo que não precise da intermediação dos dogmas positivistas. Paziani e Perinelli Neto arrematam:

\footnotetext{
Em outras palavras, para que a verdade do (e no) conhecimento histórico reconquiste sua legitimidade científica, será necessário pensá-la como um ponto de chegada, e não de partida, já que os limites entre o verdadeiro, o fictício e o falso são tênues, porém delimitáveis pelas chamadas "zonas opacas" - "alguns dos rastros que um texto (qualquer texto) deixa atrás de si”. (GINZBURG, 2007b, p. 12, apud PAZIANI e PERINELLI NETO, 2018, p. 330).

São esses "rastros", ou dados negligenciáveis, que permitem ao historiador afeito ao indiciarismo construir narrativas passíveis de ir além da própria narratividade e comprometer-se com o problema da verdade - desde que historicamente situada e determinada. E isto, assinalou Ginzburg, "mesmo quando envolver verdades desagradáveis e dolorosas" (PALLARESBURKE, 2000, p. 299, apud PAZIANI e PERINELLI NETO, 2018, p. 330).
}

Assim, o paradigma indiciário, método oriundo da História baseado na interpretação de sinais, símbolos, indícios e demais elementos conjuntivos, pareceu-nos adequado por abrir a via ao entendimento de como os autores pensavam a Geografia de sua época por meio de palavras aparentemente banais, 
Os métodos das ciências, o paradigma indiciário e as pesquisas documentais em Geografia: Uma proposta aplicada

sentenças curtas ou aforismos pretensamente não intencionais. Todavia, ao contrário do que se possa pensar, não se trata de abstrair quaisquer interpretações, extrapolando os limites da subjetividade. A busca pela verdade, enquanto valor objetivo, está no cerne dessa proposta.

\section{APLICAÇÃO DO MÉTODO PARADIGMA INDICIÁRIO EM PESQUISAS DO TIPO DOCUMENTAL}

A pesquisa documental que empreendemos dedicou-se à investigação de cinco livros didáticos de Geografia, com ênfase em conteúdos de climatologia escolar, contemplando autores representativos da Geografia escolar brasileira durante o período de 1967 a 2013. Selecionamos, a esse propósito, alguns trechos em que o paradigma indiciário, ou indiciarismo, pôde ser empregado com aproveitamento para a compreensão do texto e como chave para acessar as possíveis intenções dos autores em seus discursos.

Os trechos que selecionamos para este artigo são extraídos de dois livros didáticos, que fazem parte da mesma coleção: O Mundo em que vivemos, edição de 1967, e Terra brasileira, edição de 1968. Ambos os livros são de autoria de Aroldo de Azevedo. Ele foi um importante autor de livros didáticos de Geografia entre as décadas de 1940 e 1970, seguindo uma linha pioneira inaugurada, na década de 1920, pelo professor Carlos Miguel Delgado de Carvalho.

A origem e a trajetória de Aroldo de Azevedo se refletem muito em suas obras: Segundo Santos (1984, p. 8-9), Aroldo de Azevedo foi um homem proveniente da elite paulista de sua época, a saber, o período entre o fim do Segundo Império e a Primeira República. Era neto, do lado paterno, de Antonio Rodrigues de Azevedo, o Barão de Santa Eulália, rico cafeicultor do Vale do Paraíba paulista e político da então província de São Paulo, no tempo do Segundo Império. Seu pai, Arnolfo Rodrigues de Azevedo, foi um proeminente parlamentar da Primeira República, na época da política que ficou conhecida como "café com leite", dada a alternância de poder entre São Paulo e Minas Gerais.

Sua mãe também provinha de família abastada e tradicional. Ela era filha do urbanista Ignácio Cochrane, este oriundo de antiga estirpe paulista e monarquista, cujas origens podem ser remontadas aos tempos coloniais e cujos descendentes destacaram-se como embaixadores, diplomatas e em altos postos 
em cargos públicos. Aroldo apreciava sua ascendência, externando orgulho em obras biográficas e genealógicas que passou a compor ao final de sua carreira, com o intuito de enaltecer seus antepassados. Segundo Santos (1984, p. 11-12), o orgulho de sua origem e de sua classe socioeconômica conduzia-o a uma postura elitista, que parece ter influenciado suas atividades sociais, seu pensamento e sua obra.

À luz do paradigma indiciário, trazemos aqui dois trechos de suas obras didáticas. No primeiro trecho, que aparece na Figura 1, Aroldo discorre a respeito da cultura e da civilização (no livro O Mundo em que vivemos), tecendo considerações muito particulares, que refletem sobremaneira a forma como ele enxerga a civilização e o papel de tutela que cabe aos povos por ele considerados "civilizados" sobre os "primitivos" e os "semicivilizados". No segundo trecho, que aparece na Figura 2 (extraído do livro Terra brasileira), Aroldo apresenta a sua visão de povo brasileiro, em cujo discurso - entre afirmações ufanistas e omissões às causas das diferenças sociais - é possível captar os rastros que o ligam a um pensamento conservador e elitista.

No trecho selecionado da Figura 1, Aroldo divide os povos em graus de civilização. Chama os menos civilizados de selvagens ou primitivos, que conhecem somente as formas mais rudimentares de cultura. Os semicivilizados, ou bárbaros, são aqueles que possuem, a seu entender, algumas atividades culturais: o respeito à família, a profissão de alguma fé religiosa - politeísta ou monoteísta -, a busca pelo aprimoramento da linguagem e pela instituição de leis e, ainda, um governo organizado. 
Figura 1: A vida humana

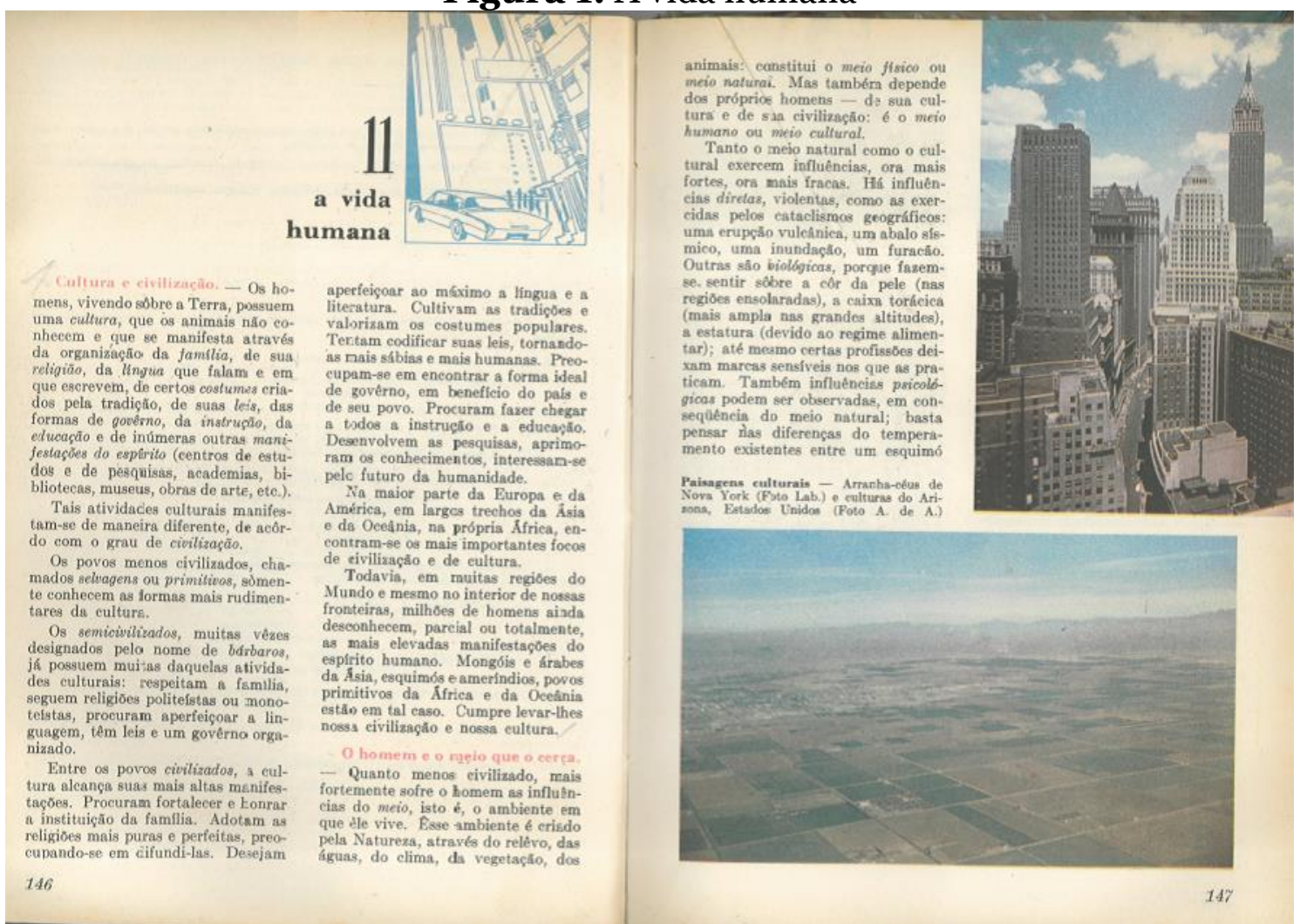

Fonte: AZEVEDO, Aroldo de. O Mundo em que vivemos. $5^{\text {a }}$ edição. São Paulo: Companhia Editora Nacional, 1967.

A categoria "civilizados" abrange aqueles povos cuja cultura alcançou as mais altas manifestações. Para Aroldo, as mais altas manifestações compreendem fortalecer e honrar a instituição da família, adotar as religiões mais puras e perfeitas - preocupando-se em difundi-las -, aperfeiçoar ao máximo a língua e a literatura, cultivar tradições populares, codificar leis a fim de torná-las mais sábias e humanas, preocupar-se em encontrar a forma ideal de governo, em benefício do país e de seu povo, e preocupar-se em estender a todos a instrução e a educação.

Pelo trecho em destaque, já é possível notar os traços que distinguem os civilizados dos não civilizados, na visão do autor. Enquanto os selvagens não dispõem de leis para a ordem social, os bárbaros já possuem algumas, ainda que incompletas ou limitadas. Os civilizados é que disporiam das leis as mais elaboradas e acabadas para uso em sua sociedade e, por que não, para a tutela dos não civilizados. Chama a atenção, igualmente, o trecho em que ele diz serem as religiões dos povos civilizados as mais puras e perfeitas, cabendo-lhes a sua difusão. Ora - podemos nos questionar -, e o que seria uma religião mais pura e perfeita, em relação a religiões praticadas por povos considerados atrasados? 
Aroldo não chega a apontar que religião é essa, mas fica explícito que a religião do civilizado deve se impor à do não civilizado.

Porém, o trecho mais chamativo é aquele em que Aroldo assim diz, na página 146 da Figura 1:

Todavia, em muitas regiões do Mundo e mesmo no interior de nossas fronteiras, milhões de homens ainda desconhecem, parcial ou totalmente, as mais elevadas manifestações do espírito humano. Mongóis e árabes da Ásia, esquimós e ameríndios, povos primitivos da África e da Oceânia (sic) estão em tal caso. Cumpre levar-lhes nossa civilização e nossa cultura (grifo nosso).

Evidentemente, nosso momento histórico atual não mais permite inferências tão explícitas como a que está em destaque no trecho, por portar uma visão elitista e imperialista, e talvez até maniqueísta, do que é civilização e cultura. Poderíamos nos questionar o porquê de termos de levar nossa civilização e nossa cultura àqueles que cultivam outras tradições. Essa obsessão de Aroldo em destacar a superioridade da cultura ocidental frente a outras culturas asiática, árabe, ameríndia, africana - e de levá-las aos supostamente menos favorecidos faz-nos recordar, guardadas as devidas proporções, as missões religiosas dos séculos XVI, XVII e XVIII, que partiam a aculturar e a tutelar o gentio das terras desbravadas pelos europeus.

Esse é um trecho que denota a visão elitista do professor Aroldo. Quando ele pugna a necessidade de expansão da "nossa civilização e nossa cultura" (no caso, a cultura ocidental) sobre os povos considerados menos afortunados, ele expõe a seu público - alunos do Ensino Médio - uma visão de mundo bastante particular, baseada na sua formação e nos seus valores pessoais. 
Figura 2: País de contrastes

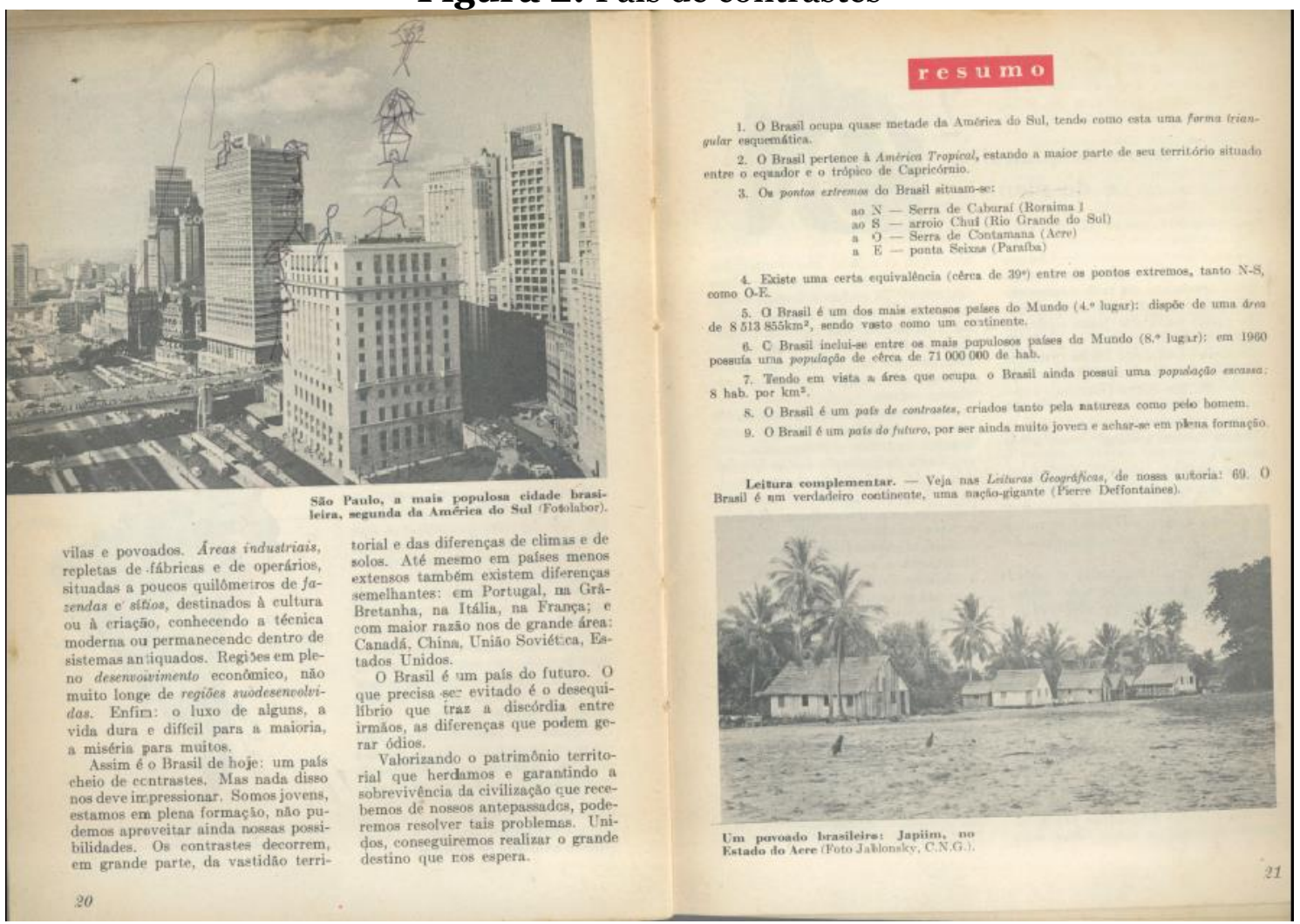

Fonte: AZEVEDO, Aroldo de. Terra brasileira. $41^{\mathrm{a}}$ edição. São Paulo: Companhia Editora Nacional, 1968.

O trecho que ora reproduzimos, constante nas páginas 19 e 20, revela o pendor de Aroldo a um otimismo exacerbado e escamoteador da realidade:

O Brasil é um país de contrastes - Basta percorrer as terras brasileiras de norte a sul ou de leste a oeste, e logo notaremos a existência de diferenças, de muitos contrastes. Há contrastes criados pela natureza [...]. Outros contrastes foram criados pelo homem, em contato com a natureza, ao povoar o país, ao ocupar suas terras e ao dedicar-se às diferentes atividades econômicas. [...] No entanto, apesar de todos êsses contrastes, não existem ódios a separar uns dos outros. Todos se consideram como irmãos, filhos de uma Pátria só. Todos falam uma só língua - o português. Esmagadora maioria segue uma única religião - o Catolicismo. Mas outros contrastes humanos ainda existem. Grandes cidades, movimentadas e modernas [...] ao lado de um número maior de cidades médias e pequenas, de vidas e povoados. Áreas industriais [...] situadas a poucos quilômetros de fazendas e sítios [...]. Regiões em pleno desenvolvimento econômico, não muito longe de regiões subdesenvolvidas. Enfim: o luxo de alguns, a vida dura e difícil da maioria, a miséria para muitos. Assim é o Brasil de hoje: um país cheio de contrastes. Somos jovens, estamos em plena formação, não pudemos aproveitar ainda nossas possibilidades. Os contrastes decorrem, em grande parte, da vastidão territorial e das diferenças de climas e de solos [...]. O Brasil é o país do futuro. $\underline{\text { O que precisa ser evitado é o desequilíbrio que traz discórdia }}$ 
entre irmãos, as diferenças que podem gerar ódios. Valorizando o patrimônio territorial que herdamos e garantindo a sobrevivência da civilização que recebemos de nossos antepassados, poderemos resolver tais problemas. Unidos, conseguiremos realizar o grande destino que nos espera (grifos nossos).

Há alguns comentários que podemos tecer. Aroldo fornece diversos indícios sobre a forma como ele pensa a sociedade brasileira, ou, antes, o futuro que ele vislumbra para o Brasil. O primeiro deles refere-se à mitigação das divergências entre pessoas e grupos sociais. $\mathrm{O}$ autor assume-nos como irmãos, expondo que há contrastes, isto é, diferenças culturais, mas negando a existência de ódios separatistas entre compatriotas. Tal afirmação é, no mínimo, descabida. Basta-nos lembrar a história do Brasil colonial e imperial para admitir que sempre houve rusgas entre diferentes regiões e suas lideranças para com o governo central, cujos laivos separatistas ainda insistem em sazonalmente ecoar. ${ }^{16}$

Um ponto de realismo que destoa do discurso ufanista é o trecho em que Aroldo diz "o luxo de alguns, a vida dura e difícil da maioria, a miséria para muitos". Para todos os efeitos, ele admite haver, sim, um sério problema de ordem econômica e social a ser encarado pela jovem nação promissora. Admitir que alguns desfrutam do luxo, a maioria tem vida dura e difícil e muitos têm uma existência miserável equivale a dizer que a distribuição de renda no país está longe de ser razoavelmente justa.

$\mathrm{O}$ argumento poderia ser desenvolvido, expondo-se alguns porquês de a nossa sociedade estar assim estruturada. Porém, o que se lê, na sequência, é uma justificativa pouco convincente, assentada em explicação simplista: por sermos uma nação jovem e em formação, não pudemos aproveitar as possibilidades que o meio generosamente nos oferece. Ao usar o termo "possibilidades", Aroldo parece apoiar-se sobre o pensamento lablachiano/possibilista para sustentar sua ideia de que basta completarmos nossa formação como país para superarmos o atraso e as diferenças.

\footnotetext{
${ }^{16}$ A melhor menção que podemos fazer é a Revolução Farroupilha, cujo intuito era separar a então província de São Pedro do Rio Grande do Sul do restante do país. Não à toa, rumores de uma possível separação daquele estado são eventualmente ouvidos, o que evidencia que as diferenças do passado não foram completamente superadas e que, contrariamente ao que propaga Aroldo - sem entrar no mérito se ingênua ou intencionalmente -, a fraternidade entre brasileiros é mais quimérica do que real.
} 
Os métodos das ciências, o paradigma indiciário e as pesquisas documentais em Geografia: Uma proposta aplicada

Discordamos, naturalmente, de sua visão; se muitos viviam - e ainda vivem em situação de penúria, desprovidos dos mais básicos recursos para o atendimento de suas necessidades pessoais, não é, certamente, em função das razões alegadas pelo autor. As desigualdades e injustiças estão muito mais ligadas à nossa formação sócio-histórica do que à vastidão territorial e às diferenças de climas e de solos.

Quanto ao trecho em que faz apelo a que se evitem discórdias entre irmãos e as diferenças que podem gerar ódios, fica bem claro o conservadorismo de Aroldo. O temor de que pudesse haver discórdias entre brasileiros em razão das grandes desigualdades e flagrantes injustiças, que ele mesmo faz menção, traz à tona o fantasma da insatisfação popular, gérmen de futuras revoluções. Para alguém com a mesma origem e criação do autor, nada pior do que a sedição, isto é, a completa subversão da ordem social vigente e a substituição por uma nova, talvez mais justa e baseada em princípios de isonomia. Por isso, inferimos, sua admoestação a se evitar qualquer conduta que fugisse do padrão de docilidade que se espera dos brasileiros.

Aroldo termina o capítulo com a mensagem de que os brasileiros, unidos, conseguirão cumprir o grande destino que lhes espera, pois o Brasil é país do futuro, pleno de possibilidades - desde que o povo saiba o lugar que lhe cabe. Seu otimismo ufanista maquia a realidade a ponto de o autor assumir que basta a valorização do patrimônio territorial e da manutenção da cultura herdada dos colonizadores para conseguirmos resolver os problemas que nos afligem. Tratase de um discurso que revela, como aponta Santos (1984, p. 55), a falta de criticidade do autor e sua tentativa de manter uma narrativa neutra e isenta, mesmo diante de uma realidade muito longe da ideal.

\section{CONSIDERAÇÕES FINAIS}

As questões dos métodos nas ciências são sempre amplas, porque os métodos não são fechados, a começar por sua própria definição: um método pode ser compreendido de forma distinta na comunidade científica, e mesmo um método reconhecido por um pesquisador pode não ser reconhecido por outro pesquisador de forma tão pacífica.

Parece claro que os métodos comumente empregados pelas ciências naturais - experimentação, indução e dedução - não se aplicam com tanta 
eficácia às ciências humanas, em razão do objeto muito particular, a saber, o homem e suas produções intelectuais. Isso obriga o pesquisador da área de ciências humanas a recorrer a outros métodos que permitam investigar o homem e toda a sua gama de manifestações de modo a melhor atender aos objetivos das pesquisas dessa área.

Os estudos em ciências humanas do tipo documentais não permitem, obviamente, que o pesquisador empregue os métodos habitualmente empregados pelas ciências naturais. O aporte matemático, apanágio destas, também não se podem aplicar àquelas. Assim, uma opção metodológica possível às pesquisas documentais são os métodos de tipo hermenêutico, em que se emprega, via de regra, a interpretação com caminho para elucidação do objeto investigado. Contudo, tradicionalmente a hermenêutica se pauta na observação das regularidades, daquilo que é semelhante no conjunto de fenômenos, do singular entre os elementos observados.

O paradigma indiciário, assim chamado por Ginzburg (2016), emerge como possibilidade metodológica dentro da ampla variedade da hermenêutica. Método oriundo da História, ele centra sua atenção no marginal, nos detalhes, nos resíduos, nos rastros, em elementos, palavras ou sentenças que podem passar despercebidos aos olhos desatentos. Ao pesquisador na área de ciências humanas que faz investigação documental, é um caminho excelente que abre as vias para compreender as possíveis intenções dos autores, considerados os contextos histórico-sociais do período analisado e as características das obras selecionadas, com foco para a busca de verdades objetivas que só podem ser alcançadas por meio do olhar atento aos detalhes.

\section{REFERÊNCIAS}

ABBAGNANO, Nicola. Dicionário de filosofia. $2^{\mathrm{a}}$ ed. São Paulo: Mestre Jou, 1982.

ALVES-MAZZOTI, Alda Judite e GEWANDSZNAJDER, Fernando. O método das ciências naturais e sociais: pesquisa quantitativa e qualitativa. $2 .^{\mathrm{a}} \mathrm{ed}$. São Paulo: Pioneira Thompson Learning, 2001.

AZEVEDO, Aroldo de. O Mundo em que vivemos. $5^{\text {a }}$ edição. São Paulo: Companhia Editora Nacional, 1967.

Nacional, 1968.

Terra brasileira. $41^{\mathrm{a}}$ edição. São Paulo: Companhia Editora 
BOUDON, R. Les sciences humaines sont-elles des sciences ? Enciclopédie Philosophique Universelle. Paris: Press Universitaires de France, 1991.

\section{CHINAZZO, Suzana Salete Raymundo. Epistemologia das Ciências}

Sociais. Curitiba: InterSaberes, 2013.

DEMO, Pedro. Pesquisa e Construção de Conhecimento - Metodologia científica no caminho de Habermas. $3^{0}$ ed., Rio de Janeiro: Tempo Brasileiro, 1997.

FERREIRA, Aurélio Buarque de Holanda. Miniaurélio: o minidicionário da língua portuguesa. $6^{\mathrm{a}}$ ed. $8^{\mathrm{a}}$ reimpressão. Curitiba: Positivo, 2004.

FRODEMAN, Robert. A Epistemologia das Geociências. In: MARQUES, Luís; PRAIA, João (coord). Geociências nos currículos dos ensinos básico e secundário. Aveiro: Universidade de Aveiro, 2001.

GINZBURG, Carlo. Mitos, emblemas, sinais: morfologia e história. Tradução de Federico Carotti. $2^{\mathrm{a}}$ ed. $7^{\mathrm{a}}$ impressão. São Paulo: Companhia das Letras, 2016.

PAZIANI, Rodrigo Ribeiro e PERINELLI NETO, Humberto. A linguagem posta à prova pelo tempo: Carlo Ginzburg e as contribuições para a História da Educação. Revista de História e Educação, Porto Alegre, v. 22, n. 55, maio/ago. 2018, p. 314-333. Disponível em <https://seer.ufrgs.br/asphe/issue/view/2980/showToc > . Acesso em 22 jun. 2020.

POTAPOVA, M. S. Geologia como uma ciência histórica da natureza. In: Terrae Didatica, 3 (1): 86-90, 2008. Disponível em < https://ocs.ige.unicamp.br/ojs/terraedidatica/article/view/1021>. Acesso em 22 jun. 2020.

LALANDE, André. Vocabulário - Técnico e Crítico - da Filosofia. Vol. I e II, Porto, Portugal, Rés Editora, s.d.

RAMPAZZO, Lino. Metodologia científica: para alunos dos cursos de graduação e de pós-graduação. $7^{\mathrm{a}}$ ed. São Paulo: Loyola, 2013.

RICEUR, Paul. Expliquer et comprendre. Sur quelques connexions remarquables entre la théorie du texte, la théorie de l'action et la théorie de l'histoire. Revue Philosophique de Louvain. Quatrième série, tome 75, n. 25, 1977, p. 126-147. Disponível em <http://www.persee.fr/doc/phlou_oo353841_1977_num_75_25_5924>. Acesso em 22 jun. 2020.

Interpretação e ideologias. $4^{\mathrm{a}}$ ed. Tradução de Hilton Japiassu. Rio de Janeiro: Francisco Alves, 1990.

RUIZ, João Álvaro. Metodologia científica: guia para eficiência nos estudos. $4^{\mathrm{a}}$ ed. São Paulo: Atlas, 1996. 
SANTOS, Boaventura de Sousa. Um discurso sobre as Ciências na transição para uma ciência pós-moderna. Revista Estudos Avançados. São Paulo, Universidade de São Paulo, v. 2, n. 2, p. 46-71, 1988. Disponível em <http://www.revistas.usp.br/eav/issue/view/665>. Acesso em 22 jun. 2020.

SANTOS, Wilson dos. A obra de Aroldo de Azevedo - uma avaliação. 1984. 98 f. Dissertação (Mestrado em Geografia) - Instituto de Geociências e Ciências Exatas, Universidade Estadual Paulista, Rio Claro.

SEIBT, Cesar Luis. Dupla estrutura do conhecimento em Heidegger - explicar e conhecer. Revista Peri. Florianópolis, Universidade Federal de Santa Catarina, v. 8, n. 1, p. 230-241, 2016. Disponível em <http://www.nexos.ufsc.br/index.php/peri/article/view/1252>. Acesso em 22 jun. 2020.

ZIMAN, J. O conhecimento confiável: uma exploração dos fundamentos para a crença na ciência. Tradução de Tomás Bueno. São Paulo: Papirus, 1996.

Recebido em 10 de Setembro de 2020 Aceito em 30 de Novembro de 2020 